\title{
Digital Library of personalized information services approach and Countermeasures
}

\author{
Qingsong Zhang \\ Library \\ Jilin Agricultural University \\ Changchun,,China \\ 729738677@qq.com \\ $+8615604305161$
}

\author{
Xinyu Wang \\ Library \\ Jilin Agricultural University \\ Changchun,,China \\ lxy@jlau.edu.cn
}

\begin{abstract}
- personalized information service is an important trend in the development of digital libraries. On the basis of the analysis of user needs and the necessity Digital Library of personalized information services, we propose a personalized information services, the main form and service strategies.
\end{abstract}

Key Words- digital library; personalized service; strategy

\section{INTRODUCTION}

Personalized information service is an important trend in the development of digital libraries is to attract users to participate in the digital library construction is the key. The so-called personalized information service is the information service in accordance with the user's preferences, habits and characteristics carried out. It is carried out for each user's unique information needs of targeted services, the information of interest to recommend it to the user, and thus meet the individual needs of users.

\section{THE NECESSITY OF A DIGITAL LIBRARY OF PERSONALIZED INFORMATION SERVICES}

In the information age to the network represented, with increasingly specialized division of labor in today's world, fine, people's demand for more specialized information, vertically oriented, for the rapid dissemination of information the Internet provides a convenient conditions. However, based on the inherent characteristics of the Internet, online disorderly filled with massive information, and information on the various types of the members have their own specific needs, which resulted in a conflict with the individual needs of information between the disorder. Digital Library of personalized information services is driven in such conflicts born out of.

\section{DIGITAL LIBRARY USER NEEDS ANALYSIS}

Opening of information needs, socialization. Development of digital library information resources to break the regional and limitations. Readers can be accepted by the library service to users to access digital library website. The global network makes this service gradually into every corner of the globe. Compared with the traditional library, digital library user is no longer fixed, they realize the sharing of information resources in an open, interactive environment. Digital library is open to the weather to the user , user access , retrieval , access library website information resource constraints of time suffered minor ${ }^{[1]}$.

Information needs simple and humane. In the Internet environment, extensive source of digital library users , most users can not have high expertise and knowledge retrieval offline and online retrieval required, generally no professional searchers to whom services, the vast most are self- retrieval. In this case, the simplicity of a digital library system and friendliness is particularly important.

Diverse information needs of dynamic. With the interpenetration of interdisciplinary, extended from the original one-sided information needs of the user to diverse information needs. In the form of user information required from the original text in the form of a simple extension to the text , images, sound and other forms.

Informative information needs. In the network environment, the reader 's information needs of library service needs from a simple shift literature literature service, inquiry service , integrated information service needs more than document delivery services , online search services , reference services, such as one .

\section{MAIN WAYS A DIGITAL LIBRARY OF PERSONALIZED INFORMATION SERVICES}

Kind of personalized information service range, but its essence is to take a different service policies for different users, providing content users need. In recent years, digital libraries around the world a wide variety of personalized information services, but there are several summed up the main form .

\section{A. custom personalized content service}

Personalized content customized services mainly refers to the user according to their needs and purposes, to a particular system to submit their own search interface preferences resources, system services and other information. It does this by obtaining information of individual users , to provide users with more accurate information service satisfaction, and thus become a digital library of personalized information services, the most important way . Personalized content customized services customized content is very rich, including interfaces, resources, services, and resources, which means that users are most concerned about the content of the resource of interest to the user. Include: databases, electronic journals , websites, 
multimedia resources, and so on .

\section{B. custom personalized information retrieval service}

Perfect network information service environment is to carry out personalized information services necessary prerequisite to constantly improve the network infrastructure library information services, and ways to integrate a variety of services and integration, and gradually establish includes OPAC, database queries, online SDI Consulting (SDI), interlibrary loan, document delivery, online user education, comprehensive service system. Information integration services is, to a large number of distributed resources according to certain themes, certain tasks intelligence gathering and retrieval services through a unified and ultimately achieve a combined effect of service information resources $^{[2]}$. The main purpose of interoperability of information resources is to create a resource for accessing different databases unified interface, thus enhancing information integration services to improve the interoperability of information resources should be the focus of library resources construction.

\section{Vertical Information Services}

Information relative to the vertical level of service in terms of information services, by providing specialized and personalized services to enable users to get more professional and more in-depth services, and the utilization of information and intelligence has been greatly improved [ 6 ] . Information is a resource, but only the information required for efficient use of such resources can be integrated into a tool. From this mass of information and poor information, like do not give rise to the utility, facing the era of information explosion , the first in a broad array of information that people often pale, I do not know how to find the information they need . This requires specialized digital library

\section{D. personalized knowledge mining services}

Personalized knowledge mining services largely due to the emergence and development of data mining technology in the networking field. Web data mining can automatically discover and extract documents from the Web information, and make the necessary comparison, classification and analysis, users do not need to provide customized and subjective wishes, a track user behavior and user preferences to automatically push the field from the database similar content $^{[3]}$.

\section{DIGITAL LIBRARY OF PERSONALIZED INFORMATION SERVICES TO IMPLEMENT STRATEGIES}

\section{A. build a user-centric services, improving customer relationships .}

Advantage of personalized information services does not mean that all users will consciously take personalization behavior, due to security considerations , privacy and other aspects of the process cumbersome, users sometimes tend to reject personalized information services. Key to the success of personalized information services lies in its ability to obtain the trust of users, users can eliminate concerns consciously accept the personalized information services to take personalization behavior. Librarians and users to foster good relations, gradually transforming the relationship is like a past reference sincere partnership of mutual trust between the doctor and patient ${ }^{[4]}$. User-centric focus of information services required libraries will be transferred to practical needs of users up. Providing personalized information services to ensure that this service is not a mere formality, but truly from the actual needs of users, where users can obtain a larger convenience, rather than trouble. At the same time, to respect the user.

\section{B. improving basic information services, focusing on information integration and interoperability .}

Perfect network information service environment is to carry out personalized information services necessary prerequisite , on the one hand , the user only after the basic information needs are met before to consider their individual information needs. On the other hand, to carry out personalized information service depends on sound information services provide support, such as resource navigation, building networks and other characteristics of the database . Therefore, the library information network infrastructure to continuously improve services, and ways to integrate a variety of services and integration , and gradually establish includes OPAC, database queries, online consulting SDI (SDI), interlibrary loan , document delivery , online user education, comprehensive service system . Information integration services is, to a large number of distributed resources according to certain themes, certain tasks intelligence gathering and retrieval services through a unified and ultimately achieve a combined effect of service information resources . Due to the current data format, the user interface is not uniform for each database to the user 's information retrieval great inconvenience, but also hindered the provision of personalized information services. The main purpose of interoperability of information resources is to create a resource for accessing different databases unified interface, thus enhancing information integration services to improve the interoperability of information resources should be the focus of library resources construction.

\section{Find key, and gradually expand the personalized information service}

Due to technical reasons, time, energy and other aspects of the library is not possible to carry out large-scale personalized information services. Each library should be considered its own resources, service goals, user needs, capital, technology and personnel conditions, identify the entry point. Under the conditions permit, and gradually expand the personalized information service mode, explore ways to achieve personalized information services ${ }^{[5]}$. First, the implementation of personalized information services 
should be limited to the internal network . Personalized information services to create a user model for each user , providing a specific service, is a very time-consuming and energy work, in the early implementation of the personalized information service only confined to the museum inside the legitimate user . Considerations of intellectual property rights, privacy and system security, etc. , to open for all Internet users is not realistic . Personalized information service from the formal point of view , there are multiple levels to choose from.

\section{CONCLUSION}

In short , personalized information services should also be the dominant service mode will become the future of digital libraries . Building a digital library should face this challenge and build a user-centric information service platform, which is both meet the evolving information needs of the user requirements, but also requires the existence and development of the library .

\section{REFERENCES}

[1]Xu Jiefei. Personalized Digital Library Research Service Summary [J]. Information Research,2010(7):116-118.

[2]Li Li. University Digital Library Personalized Service Mode[J]. Lantai World, 2012(7):91-92.

[3]Sun Junsheng, Li Heqin. Digital Library of personalized service approach and development trend[J]. Library and Information Service,2010(2):199-203.

[4]Lu Xiaolin. Colleges Digital Library of personalized service[J]. Lantai World,2011(21):48-50.

[5]Xie Wei. An Analysis of Trends and Strategies Digital Library[J]. Information Studies:Theory \& Application, 2009(4):51-53. 